\title{
Diabetic foot ulcers: treatment overview and cost considerations
}

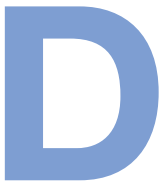

iabetic foot ulcers (DFUs) are deep tissue lesions associated with ischaemic, neuropathic, or combined neuroischaemic abnormalities and are a leading cause of morbidity and mortality. ${ }^{1,2}$ Of concern is that DFUs affect multiple areas of a person's functioning, including both physical and psychological distress. ${ }^{3,4}$ For example, inactivity due to a DFU can cause feelings of frustration, anger and guilt in patients. ${ }^{5,6}$ This distress has the potential to impair the immune response as well as impacting the quality of life (QoL) ${ }^{7-9}$

DFUs are often complicated by the presence of infection and this combined with abnormalities are a key cause of amputation in patients with DM, indeed up to $85 \%$ of lower extremity amputations are preceded by the presence of a DFU. ${ }^{10}$ Furthermore, even when treatment plans are followed, not all DFUs heal, and those that do have a high rate of recurrence. ${ }^{11,12}$

Numerous epidemiological studies on DFUs have reported an elevation in the incidence of DFUs due to a greater life expectancy in patients with diabetes and an increasing worldwide prevalence of diabetes within an ageing population..$^{10,13-15}$ DFUs are estimated to occur in one in every seven patients with diabetes. ${ }^{16-18}$ Furthermore, a recent systematic review showed the global prevalence of DFUs at 6.3\% (95\% confidence interval (CI): 5.4-7.3\%), with the prevalence in North America, Asia, Europe, Africa and Oceania at $13.0 \%$ (95\%CI: $10.0-15.9 \%), 5.5 \%$ (95\%CI: 4.6-6.4\%), 5.1\% (95\%CI: $4.1-6.0 \%)$, 7.2\% (95\%CI: $5.1-9.3 \%$ ), and $3.0 \%$ (95\% CI: $0.9-5.0 \%)$ respectively. ${ }^{19}$ The cost of DFUs varies depending on the degree of ulceration and the underlying pathologies which gave rise to the ulceration in the first place. The cost of DFUs increases with the severity of the lesion and is also dependent on the interventions used to treat them. ${ }^{20}$

The management of DFUs is complex and multifaceted, thus, care delivery is best using a team approach. ${ }^{10,21-23}$ However, this complexity means that patients often must place significant restrictions on their daily lives. For example, it is usual that patients may be asked to attend multiple appointments with different specialists, restrict their physical movement, change their diet or take different medications, resulting in an impaired QoL. ${ }^{12}$ Interestingly, patients with diabetic foot amputation with mobilisation capacity have a higher QoL compared with patients with a DFU. ${ }^{24,25}$

The overall management of DFUs involves

\section{Zena Moore}

Professor of Nursing, Head of School of Nursing and Midwifery and Director of the Skin Wounds and Trauma Research Centre. RCSI University of Medicine and Health Sciences, Dublin;

Adjunct Professor, Fakeeh College of Health Sciences, Jeddah, Saudi Arabia;

Adjunct Professor, Faculty of Medicine, Nursing and Health Sciences, Monash University, Australia;

Professor, Department of Public Health, Faculty of Medicine and

Health Sciences, Ghent University, Belgium;

Honorary Professor, Lida Institute, Shanghai, China;

Visiting Professor, University of Wales, Cardiff, UK;

Adjunct Professor, Griffith University, Australia

\section{Pinar Avsar}

pinaravsar@rcsi.com

Senior Postdoctoral Fellow. Skin Wounds and Trauma Research

Centre. The Royal College of Surgeons in Ireland (RCSI), University of Medicine and Health Sciences, Dublin

\section{Pauline Wilson}

Skin, Wounds and Trauma Research Centre, School of Nursing and Midwifery. RCSI University of Medicine and Health Sciences, Dublin Maisoon Mairghani

Skin, Wounds and Trauma Research Centre, School of Nursing and Midwifery. RCSI University of Medicine and Health Sciences, Dublin Tom O'Connor

Director of Academic Affairs and Deputy Head of School, School of Nursing and Midwifery and Lead Researcher, Skin Wounds and Trauma Research Centre, RCSI University of Medicine and Health Sciences, Dublin;

Honorary Professor, Lida Institute, Shanghai, China;

Adjunct Professor, Fakeeh College of Health Sciences, Jeddah, Saudi Arabia;

Adjunct Professor, Griffith University, Australia

Linda Nugent

Lecturer and Programme Director, School of Nursing and Midwifery. The Royal College of Surgeons in Ireland (RCSI), University of Medicine and Health Sciences, Dublin;

Adjunct Assistant Professor, Fakeeh College of Health Sciences, Jeddah, Saudi Arabia

\section{Declan Patton}

Director of Nursing and Midwifery Research and Deputy Director of the Skin, Wounds and Trauma Research Centre, School of Nursing and Midwifery, RCSI University of Medicine and Health Sciences, Dublin;

Adjunct Associate Professor, Fakeeh College of Health Sciences, Jeddah, Saudi Arabia;

Honorary Senior Fellow, Faculty of Science, Medicine and Health, University of Wollongong, Australia;

Adjunct Professor, Griffith University, Australia

interventions to address the underlying systemic pathologies which give rise to the DFU. In addition, the local management of the ulcer revolves around the principle of offloading excess pressure, while using the TIME clinical decision support tool (CDST) would mean employing interventions such as debridement of 
devitalised tissue, management of infection, achieving wound moisture balance, and stimulation of re-epithelialisation. ${ }^{26}$ In addition pressure relief of the foot is extremely important. ${ }^{27}$

\section{What is a DFU?}

Diabetic foot ulceration occurs primarily because of trauma to the foot in a patient with diabetes with either peripheral arterial disease (PAD), neuropathy, or both. In patients with neuropathy, the hallmark feature of such injury is a lack of pain. This lack of pain and awareness of injury causes the person to continue to mobilise on damaged tissue. This continued mobilisation causes increased pressure on the foot and the pressure is significant due to the altered proprioception which occurs concomitantly with neuropathy. In patients with PAD, the hallmark feature is the presence of pain in the foot and reduced tissue vitality which leads to damage usually at the borders of the foot. In patients with both neuropathy and PAD, also known as neuroischaemic, these lesions are characterised by reduced tissue vitality and a loss of pain and are currently the most prominent globally. ${ }^{28}$

Irrespective of the underlying pathologies leading to the predisposition of DFU, once a wound is present on the foot the normal wound healing cascade is altered. ${ }^{29}$ These wounds are often stuck in the inflammation phase and unable to progress from this. ${ }^{30}$ Thus, the goal of any management strategy is to interrupt this altered process and return the wound to a normal healing cascade. In addition, interventions targeted at healing DFUs will also need to address the underlying pathologies that predisposed the individual to ulceration in the first place. ${ }^{31}$

\section{Effects of a DFU}

A DFU often takes time to heal, meaning that the patient is at an increased risk of developing an infection. ${ }^{32}$ Indeed, the longer a person has a DFU, the greater the chance of treatment failure, partly due to the ongoing complications of diabetes. ${ }^{33}$ Infection is challenging to treat in patients with diabetes due to the polymicrobial nature of infections. A resultant outcome of this is that up to $80 \%$ of amputations are preceded by a DFU. ${ }^{34}$

A DFU may have a significant impact on a patient's health-related QoL (HRQoL), namely on their relationship with others, mobility, loss of independence, increased amputation risk, and multiple, prolonged clinic visits. ${ }^{5,35,36}$ Studies have shown that patients with diabetes and foot ulcers are more depressed and have worse HRQoL than those without diabetic complications. ${ }^{37,38}$ For example, a cross-sectional study ${ }^{36}$ included 200 patients with a DFU in a study group and 200 patients with diabetes in a control group. The authors used the RAND-36 questionnaire for evaluating QoL scores for the patients in both groups. The results showed that the diabetic foot was associated with severely impaired HRQoL in both physical and mental health aspects, based on the RAND-36. Furthermore, in several other studies, many patients reported that ulcer pain interfered with sleep and that they should avoid putting pressure on the ulcer, even from bedding. Pain has also been reported when walking even short distances and during dressing changes. ${ }^{39-42}$ Clearly, pain has an obvious impact on HRQoL.

As mentioned, a DFU can be the precursor to lower extremity amputations. ${ }^{43,44}$ Another systematic review $^{43}$ aimed to explore the long-term outcomes of lower extremity amputations as a result of DFU. The authors found that re-amputations were 20.14\%, $29.63 \%$ and $45.72 \%$ at one, three and five years, respectively. The weighted mean mortality at one, three and five years was $13.62 \%, 30.25 \%$, and $50.55 \%$, respectively, with significantly higher rates associated with major amputation, re-amputation and ischaemic cardiomyopathy. Another systematic review ${ }^{44}$ focused on the role of DFU on mortality. The authors reported that the fiove-year mortality rate after ulceration was around $40 \%$.

\section{Cost of DFUs}

DFUs impose a substantial health economic burden on individuals, healthcare systems and society. ${ }^{45-47}$ These costs are comparable to that of cancer in the US, each contributing to an almost similar economic burden. ${ }^{47}$ In Europe, it is estimated that the economic burden of DFUs comes to US\$13,561 annually. ${ }^{20}$ In the US, that the total medical cost for the management of DFUs varies from US\$9-13 billion in addition to the cost for management of diabetes alone. ${ }^{46} \mathrm{~A}$ cohort study conducted in the Greater Toronto area showed that DFU was in the top five most costly conditions $(\$ 10,169)$. The authors reported that the cost per patient with a DFU was $\$ 22,754$ while the cost per patient without a DFU was $\$ 8350$.

In terms of the burden of DFUs on individuals, a study conducted in five countries including Chile, China, India, Tanzania and the US found that the cost burden of a DFU amounted to a range of between six days to 5.7 years of patient income. ${ }^{49}$ In the UK, it was found that found that DFU is responsible for $1 \%$ of the total NHS budget. ${ }^{50}$ Therefore, implementing appropriate prevention and management strategies for DFU can contribute to the achievement of quality care standards, alleviate suffering, and decrease the financial burden on healthcare and society as a whole. ${ }^{2,51}$

DFU costs encompass direct and indirect costs. Direct medical costs can be attributed to hospital admissions, emergency department visits, outpatient visits, home care, diagnostic testing, procedures, dressings, and antibiotics, ${ }^{52-54}$ whereas indirect costs are a result of reduced productivity and premature mortality. ${ }^{55}$ In general, hospital admissions and longer durations of stay account for the largest segment of healthcare expenditure. ${ }^{53}$ Indeed, when compared with other healthcare utilisation resources, including medications, hospital admissions have the highest unit costs. ${ }^{56}$ 
Therefore, cost-effective measures are necessary to reduce intervention costs in treating DFUs and thus decrease the economic burden associated with them. ${ }^{57,58}$

\section{DFU management}

A DFU arises because of a complicated interplay of multiple pathologies, all of which need to be addressed for the DFU wound to heal. Given the complexity of the DFU, care should be delivered using a multidisciplinary team approach. The TIME CDST is a model clinicians could adopt, using an ABCDE approach to ensure that each element of the care of the patient is addressed to maximise holistic patient outcomes. $^{26}$ The model includes the following key components:

- Assess patient and the wound

- Bring in multidisciplinary team and informal carers

- Control or treat systemic factors

- Decide appropriate treatment

- Evaluate and reassess wound treatment and outcomes.

This paper will address the ABC of the TIME CDST, the local wound management (D) will be addressed in a subsequent paper.

\section{Assess patient and the wound.}

Upon initial presentation, it is important to fully assess the patient, the underlying complications and pathologies, and the wound itself, and establish the presence of either PAD, neuropathy or both. To assess the level of hyperglycaemia, the measurement of glycated haemoglobin (HbA1c) is needed as is self-monitoring of blood glucose (SMBG). HBA1c can be measured either as a point of care test or with a laboratory assay, the latter showing greater accuracy. ${ }^{59}$ The measurement of HbA1c shows a mean level of blood glucose in the preceding three months. ${ }^{60}$

To assess the presence of neuropathy, bedside tests which are designed to ascertain the presence of a loss of protective sensation are employed. These tests include the use of a $10 \mathrm{~g}$ monofilament, vibration perception threshold, light touch, and/or temperature. ${ }^{61}$ This is important in clinical practice as the presence of loss of protective sensation (LOPS) is associated with a lack of awareness of injury and, as such, with an increased risk of ulceration. ${ }^{62,63}$ A combined approach is advocated for utilising more than one testing modality in order to make a diagnosis of LOPS. ${ }^{62,64}$

To assess for the presence of PAD, the initial test used is to palpate pulses as the absence of pedal pulses are associated with a high prevalence of PAD. ${ }^{65}$ The palpation of pedal pulses, both the dorsalis pedis and the posterial tibial, appear in most clinical guidelines for assessing the presence of PAD. ${ }^{66}$ Pedal pulses may still be palpable even in the presence of stenosis and non-specialists may not be clear about the location of the pulse. Studies have shown that the palpation of pedal pulses are not reliable or repeatable in specialists and non-specialists alike. ${ }^{67}$ Non-invasive vascular testing may be a useful secondary inspection tool and baseline levels of ankle-brachial indexes have been advocated in the literature, although in practice this does not necessarily happen. ${ }^{65}$ The use of Doppler waveform may help to identify those at increased risk as it allows for the assessment of the medial arterial calcification (MAC). ${ }^{66,68,69}$ At the level of the wound, it is also important to assess the local factors which may impede healing. These are the presence of infection, excess pressure and devitalised tissue.

\section{Bring in multidisciplinary team and informal carers}

It is well recognised across different health systems that multidisciplinary teams (MDTs) organise and coordinate health and care services to meet the needs of individuals with complex care needs. Teams bring together the expertise and skills of different professionals to jointly evaluate, plan and manage care. Hospital and community-based, and networked with primary health care, MDTs are expected to work proactively to support individuals' care goals. ${ }^{70,71}$

A DFU is a complex multisystem hard-to-heal wound, therefore, it requires a complex multidisciplinary approach. ${ }^{72}$ A systematic review by Musuuza et al., ${ }^{73}$ has shown that multiple single-centre studies have reported significant reductions in major amputations among patients with DFUs after initiation of multidisciplinary teams. After carefully analsysing results, while multidisciplinary team composition was variable, their involvement reduced major amputations in $94 \%$ of the studies reviewed. Clinically, teams consistently focused on and addressed glycaemic control, local wound management, vascular disease and infection, in a timely and coordinated manner to reduce major amputation for patients with a DFU. Care algorithms and referral pathways were key tools to their success. On the other hand, an earlier review found that the evidence of MDTs in the management of people with a DFU is unclear as there is much heterogentiy in published studies and reviews. ${ }^{73,74}$

\section{Control or treat systemic factors.}

The initial management plan for a DFU needs to address both the systemic challenges of hyperglycaemia, PAD, neuropathy and infection, in addition to the local management of the wound, which includes pressure relief, managing local debridement and infection, as well as ensuring the wound is dressed appropriately. ${ }^{12}$

To manage DFUs, there is a need to reduce hyperglycaemia associated with diabetes. Current guidelines recommend that the level of HbA1c should be no higher than $53 \mathrm{mmol} / 1$ to prevent the development of complications. ${ }^{75}$ Once complications have developed, the level should be maintained as close to $53 \mathrm{mmol} / 1$ as possible to prevent further exacerbation of complications. $^{75}$

Complications can lead to the presence of PAD and neuropathy in patients which predispose and complicate DFU. PAD results in reduced blood flow in 
the lower limb; this in turn complicates the wound by reducing levels of oxygenation in the foot. ${ }^{76}$ The challenge in patients with diabetes is that the disease affects the distal arteries more than the proximal arteries. Additionally, the presence of medial arterial calcification which leads to longer lesions in the artery as well as a lesion in the middle of the artery rendering the disease more difficult to treat. ${ }^{77}$ In order to effectively manage PAD, there is a need to ensure sufficient blood flow is restored to the foot to allow for any lesion to heal. ${ }^{78}$ This can be achieved via either open or endovascular means, with no difference in outcomes reported. ${ }^{78,79}$

Neuropathy is more challenging to address. The main symptom of neuropathy is that of neuropathic pain which can be very distressing as pain is felt in the absence of any lesion on the foot. ${ }^{17}$ Conversely, the presence of damage on the foot, especially to the plantar aspect, is rarely accompanied by pain. ${ }^{80}$ Both the presence of PAD and neuropathy lead to an increased risk of infection. In neuropathy, with the lack of awareness of pain, patients may continue to mobilise despite having foot wounds, leading to an increased risk of infection. Indeed, the presence of infection in wounds with neuropathy is often the cause of treatment failure and the development of systemic infection including osteomyelitis. ${ }^{81}$ The identification of the infection is often masked in the patient with a DFU and neuropathy. ${ }^{82}$

The presence of infection has important cost considerations as the extended use of systemic antibiotics is associated with high costs as well as increased rates of antimicrobial resistance. ${ }^{83,84}$ The combination of PAD, neuropathy and infection is strongly associated with a high incidence of major amputation.$^{78}$

Local treatment of infection is an area that has been under-researched and warrants further investigation. ${ }^{85}$

The effectiveness of pressure reduction to the foot with a DFU is well established in the management of neuropathic forefoot plantar ulcers (DNFU). ${ }^{74,86,87}$ The gold standard treatment is total contact casting (TCC).
There is less evidence for pressure relief in non-neuropathic lesions although the use of offloading is still advocated in clinical practice guidelines. ${ }^{88}$ Authors agree that TCC provides effective offloading of DNFUs but disagree on the mechanisms by which the offloading is delivered. ${ }^{10,89}$ Existing randomised controlled trials (RCTs) have small sample sizes and are generally underpowered and do not reflect normal practice. ${ }^{90-93}$ It has also been suggested that the use of offloading for all types of DFU is underutilised in clinical practice. ${ }^{91,94-96}$ While alternatives to TCC have been suggested, ${ }^{96-98}$ the evidence for their use is weak. ${ }^{90,99}$ Clinicians in practice need to balance the needs of the patient with the capability of the service in conjunction with published evidence. ${ }^{78,100}$

\section{Conclusion}

This clinical paper has presented an overview of the treatment and cost considerations relating to DFUs. DFUs may have a significant impact on a patient's HRQoL, namely on their relationships with others, mobility, loss of independence, increased amputation risk and multiple, prolonged clinic visits. DFU costs encompass direct and indirect costs; direct medical costs can be attributed to hospital admissions, emergency department visits, outpatient visits, home care, diagnostic testing, procedures, dressings and antibiotics. The overall management of DFUs involves interventions to address the underlying pathologies of PAD, neuropathy, and control of hyperglycaemia related to diabetes, which reduces the risk of any further acceleration of disease. The goal of the management strategy is to interrupt this process and return the wound to a normal healing cascade. Interventions targeted at healing DFU will also need to address the underlying pathologies that predisposed the individual to ulceration in the first place. This paper used the TIME CDST model to highlight how DFU treatment could be approached. This is a model that should be evaluated further in DFU care and one clinicians could consider adopting as they strive to deliver holistic patient care and better outcomes. Jwc

\section{References}

1 Aumiller WD, Dollahite HA. Pathogenesis and management of diabetic foot ulcers. JAAPA 2015; 28:28-34. https://doi.org/10.1097/01. JAA.0000464276.44117.b1

2 Yazdanpanah L, Nasiri M, Adarvishi S. Literature review on the management of diabetic foot ulcer. World J Diabetes 2015; 6:37-53. https://doi.org/10.4239/wjd.v6.i1.37

3 Ismail K, Winkley K, Stahl D et al. A cohort study of people with diabetes and their first foot ulcer: the role of depression on mortality. Diabetes Care 2007; 30:1473-1479. https://doi.org/10.2337/dc06-2313

4 Tseng CL, Sambamoorthi U, Helmer D et al. The association between mental health functioning and nontraumatic lower extremity amputations in veterans with diabetes. General Hospital Psychiatry 2007; 29:537-546. https://doi.org/10.1016/j.genhosppsych.2007.08.001

5 Alrub A, Hyassat D, Khader $Y$ et al. Factors associated with health-related quality of life among jordanian patients with diabetic foot ulcer. J Diabetes Res 2019; 2019:1-8. https://doi. org/10.1155/2019/4706720

6 Arshad MA, Arshad S, Arshad S, et al. The quality of life in patients with diabetic foot ulcers. Journal of Diabetes \& Metabolism 2020; 11:1-2. https://doi.org/10.35248/2155-6156.20.11.e101

7 Vileikyte L. Stress and wound healing. Clinics in Dermatology 2007; 25:49-55. https://doi.org/10.1016/j.clindermatol.2006.09.005

8 Hoban C, Sareen J, Henriksen CA et al. Mental health issues associated with foot complications of diabetes mellitus. Foot Ankle Surg 2015; 21(1): 49-55. https://doi.org/10.1016/j.fas.2014.09.007

9 Weinger K, Smaldone A. Psychosocial and educational implications of diabetic foot complications. The Diabetic Foot 2006; 507-521. http:// dx.doi.org/10.1007/978-1-59745-075-1_24

10 Boulton AJ, Vileikyte L, Ragnarson-Tennvall G et al. The global burden 
of diabetic foot disease. Lancet 2005; 366:1719-1724. https://doi. org/10.1016/s0140-6736(05)67698-2

11 Kee KK, Nair HKR, Yuen NP. Risk factor analysis on the healing time and infection rate of diabetic foot ulcers in a referral wound care clinic. $J$ Wound Care 2019; 28 S4-S13. https://doi.org/10.12968/jowc.2019.28. Sup1.S4

12 Schaper NC, van Netten JJ, Apelqvist $\mathrm{J}$ et al. Practical guidelines on the prevention and management of diabetic foot disease (IWGDF 2019 update). Diabetes/Metabolism Research and Reviews 2020; 36(Suppl 1): e3266. https://doi.org/10.1002/dmrr.3266

13 Zhou Q, Peng M, Zhou L et al. Development and validation of a brief diabetic foot ulceration risk checklist among diabetic patients: a multicenter longitudinal study in China. Sci Rep 2018; 8(1):962. https://doi. org/10.1038/s41598-018-19268-3

14 Bakri F, Allan A, Khader Y et al. Prevalence of diabetic foot ulcer and its associated risk factors among diabetic patients in. Jordan Medical Journal 2011; 46(2):118-125

15 Sinclair A, Dunning T, Sheu W, et al. Clinical guidelines for type 1 diabetes mellitus with an emphasis on older adults: an executive summary. Diabet Med 2020; 37(1):53-70. https://doi.org/10.1111/ dme.14135

16 Tsourdi E, Barthel A, Rietzsch $\mathrm{H}$ et al. Current aspects in the pathophysiology and treatment of chronic wounds in diabetes mellitus. BioMed Res Int 2013; 2013:385641. https://doi.org/10.1155/2013/385641 17 Singh N, Armstrong DG, Lipsky BA. Preventing foot ulcers in patients with diabetes. Jama 2005; 293:217-228. https://doi.org/10.1001/ jama.293.2.217

18 Mendes AL, Miot HA, Haddad VJ. Diabetes mellitus and the skin. An Bras Dermatol 2017; 92:8-20. https://doi.org/10.1590/ abd1806-4841.20175514

19 Zhang P, Lu J, Jing Y et al. Global epidemiology of diabetic foot ulceration: a systematic review and meta-analysis $(\dagger)$. Annals of Medicine 2017; 49:106-116. https://doi.org/10.1080/07853890.2016.1231932 20 Prompers L, Huijberts M, Schaper $\mathrm{N}$ et al. Resource utilisation and costs associated with the treatment of diabetic foot ulcers. Prospective data from the Eurodiale Study. Diabetologia 2008; 51:1826-1834. https:// doi.org/10.1007/s00125-008-1089-6

21 Nube V, Molyneaux L, Bolton T et al. The use of felt deflective padding in the management of plantar hallux and forefoot ulcers in patients with diabetes. The Foot 2006; 16:38-43

22 Delea S, Buckley C, Hanrahan A et al. Management of diabetic foot disease and amputation in the Irish health system: a qualitative study of patients' attitudes and experiences with health services. BMC Health Services Research 2015; 15:251. https://doi.org/10.1186/ s12913-015-0926-9

23 Coffey L, Mahon C, Gallagher P. Perceptions and experiences of diabetic foot ulceration and foot care in people with diabetes: a qualitative meta-synthesis. International Wound Journal 2019; 16:183-210. https:// doi.org/10.1111/iwj.13010

24 Pedras S, Carvalho R, Pereira MG. Quality of life in Portuguese patients with diabetic foot ulcer before and after an amputation surgery. International journal of behavioral medicine 2016; 23:714-721. https://doi. org/10.1007/s12529-016-9567-6

25 Pickwell K, Siersma V, Kars M et al. Minor amputation does not negatively affect health-related quality of life as compared with conservative treatment in patients with a diabetic foot ulcer: an observational study. Diabetes Metab Res Rev 2017; 33(3). https://doi. org/10.1002/dmrr.2867

26 Moore Z, Dowsett C, Smith G et al. TIME CDST: an updated tool to address the current challenges in wound care. J Wound Care 2019; 28:154-161. https://doi.org/10.12968/jowc.2019.28.3.154

27 Kaile K, Mahadevan J, Leiva K et al. Tissue oxygenation measurements to aid scalpel debridement removal in patients with diabetes. Journal of Diabetes Science and Technology 2021:1932296821992050. https://doi. org/10.1177/1932296821992050

28 Abbas ZG. The diabetic foot worldwide: Sub-Saharan Africa. The foot in diabetes (5th edn). John Wiley \& Sons Ltd., 2020

29 Frykberg RG, Banks J. Challenges in the treatment of chronic wounds. Advances in Wound Care 2015; 4:560-582. https://doi.org/10.1089/ wound.2015.0635

30 Landén NX, Li D, Ståhle M. Transition from inflammation to proliferation: a critical step during wound healing. CMLS 2016; 73 : 3861-3885. https://doi.org/10.1007/s00018-016-2268-0 31 Karri VV, Kuppusamy G, Talluri SV et al. Current and emerging therapies in the management of diabetic foot ulcers. Current Medical Research and Opinion 2016; 32:519-542. https://doi.org/10.1185/03007995.2015.11288 88

32 Game FL. Local management of diabetic foot ulcers, dressings and other local treatments. In: The diabetic foot syndrome. Piaggesi A, Apelqvist J (eds.). Karger Publishers 2018; 26:200-209 33 Caruso $\mathrm{P}$, Longo M, Gicchino $\mathrm{M}$ et al. Long-term diabetic complications as predictors of foot ulcers healing failure: a retrospective study in a tertiary-care center. Diabetes Research and Clinical Practice 2020; 163 : 108147. https://doi.org/10.1016/j.diabres.2020.108147 34 Hurst JE, Barn R, Gibson L et al. Geospatial mapping and data linkage uncovers variability in outcomes of foot disease according to multiple deprivation: a population cohort study of people with diabetes. Diabetologia 2020; 63:659-667. https://doi.org/10.1007/ s00125-019-05056-9

35 Vileikyte L. Diabetic foot ulcers: a quality of life issue. Diabetes Metab Res Rev 2001; 17:246-249. https://doi.org/10.1002/dmrr.216 36 Sekhar MS, Thomas RR, Unnikrishnan MK et al. Impact of diabetic foot ulcer on health-related quality of life: a cross-sectional study. Seminars in Vascular Surgery 2015; 28:165-171. https://doi.org/10.1053/j. semvascsurg.2015.12.001

37 Pearson S, Nash T, Ireland V. Depression symptoms in people with diabetes attending outpatient podiatry clinics for the treatment of foot ulcers. Journal of Foot and Ankle Research 2014; 7:47. https://doi. org/10.1186/s13047-014-0047-4

38 Kalra S, Jena BN, Yeravdekar R. Emotional and psychological needs of people with diabetes. Indian J Endocrinol Metab 2018; 22:696-704. https://doi.org/10.4103/ijem.IJEM_579_17 39 Ribu L, Wahl A. Living with diabetic foot ulcers: a life of fear, restrictions, and pain. Ostomy Wound Management 2004; 50:57-67. 40 Ashford RL MP, Kinmond K. Perception of quality of life by patients with diabetic foot ulcers. Diabetic Foot 2000 3:150-155 41 Meijer JW, Trip J, Jaegers SM et al. Quality of life in patients with diabetic foot ulcers. Disabil Rehabil 2001; 23:336-340. https://doi. org/10.1080/09638280010005585 42 Frescos N, Copnell B. Podiatrists' views of assessment and management of pain in diabetes-related foot ulcers: a focus group study. $J$ Foot Ankle Res 2020; 13:29. https://doi.org/10.1186/s13047-020-00399-8 43 Rathnayake A, Saboo A, Malabu UH et al. Lower extremity amputations and long-term outcomes in diabetic foot ulcers: a systematic review. World J Diabetes 2020; 11:391-399. https://doi.org/10.4239/wjd.v11. i9.391

44 Jupiter DC, Thorud JC, Buckley CJ et al. The impact of foot ulceration and amputation on mortality in diabetic patients. I: From ulceration to death, a systematic review. International Wound Journal 2016; 13: 892-903. https://doi.org/10.1111/iwj.12404

45 Carter MJ. Economic evaluations of guideline-based or strategic interventions for the prevention or treatment of chronic wounds. Applied Health Economics and Health Policy 2014; 12:373-389. https://doi. org/10.1007/s40258-014-0094-9

46 Raghav A, Khan ZA, Labala RK et al. Financial burden of diabetic foot ulcers to world: a progressive topic to discuss always. Ther Adv Endocrinol Metab 2018; 9:29-31. https://doi. org/10.1177/2042018817744513

47 Armstrong DG, Swerdlow MA, Armstrong AA et al. Five year mortality and direct costs of care for people with diabetic foot complications are comparable to cancer. J Foot Ankle Res 2020; 13:16. https://doi. org/10.1186/s13047-020-00383-2

48 Syed M, Salata K, Hussain M et al. The economic burden of inpatient diabetic foot ulcers in Toronto, Canada. Vascular 2020; 28. https://doi. org/10.1177/1708538120923420

49 Cavanagh P, Attinger C, Abbas Z et al. Cost of treating diabetic foot ulcers in five different countries. Diabetes/metabolism research and reviews 2012; 28(Suppl 1):107-111. https://doi.org/10.1002/dmrr.2245 50 Kerr M, Barron E, Chadwick P et al. The cost of diabetic foot ulcers and amputations to the National Health Service in England. Diabetic Medicine 2019; 36:995-1002. https://doi.org/10.1111/dme.13973

51 Alexiadou K, Doupis J. Management of diabetic foot ulcers. Diabetes Therapy 2012; 3:4. https://doi.org/10.1007/s13300-012-0004-9 52 Driver VR, Fabbi M, Lavery LA et al. The costs of diabetic foot: the economic case for the limb salvage team. Journal of Vascular Surgery 2010; 52:17s-22s. https://doi.org/10.1016/j.jvs.2010.06.003

53 Alshammary S, Othman SA, Alshammari E et al. Economic impact of diabetic foot ulcers on healthcare in Saudi Arabia: a retrospective study. Annals of Saudi Medicine 2020; 40:425-435. https://doi.

org/10.5144/0256-4947.2020.425

54 Joret MO, Dean A, Cao C et al. The financial burden of surgical and endovascular treatment of diabetic foot wounds. Journal of Vascular Surgery 2016; 64:648-655. https://doi.org/10.1016/j.jvs.2016.03.421 55 Kieu TTM, Trinh HN, Pham HTK et al. Direct non-medical and indirect costs of diabetes and its associated complications in Vietnam: an estimation using national health insurance claims from a cross-sectional survey. BMJ Open 2020; 10:e032303. https://doi.org/10.1136/ bmjopen-2019-032303

56 Al-Maskari F, El-Sadig M and Nagelkerke N. Assessment of the direct medical costs of diabetes mellitus and its complications in the United Arab Emirates. BMC Public Health 2010; 10:679. https://doi.

org/10.1186/1471-2458-10-679 
57 Woods TJ, Tesfay F, Speck P et al. Economic evaluations considering costs and outcomes of diabetic foot ulcer infections: a systematic review. PloS One 2020; 15:e0232395. https://doi.org/10.1371/journal. pone.0232395

58 Chan B, Campbell K. An economic evaluation examining the cost-effectiveness of continuous diffusion of oxygen therapy for individuals with diabetic foot ulcers. International Wound Journal 2020; 17. https://doi.org/10.1111/iwj.13468

59 Marshall SM, Barth JH. Standardization of HbA1c measurements: a consensus statement. Ann Clin Biochem 2000; 37(Pt 1):45-46. https://doi. org/10.1258/0004563001901506

60 Hirst JA, McLellan JH, Price CP, et al. Performance of point-of-care $\mathrm{HbA1c}$ test devices: implications for use in clinical practice - a systematic review and meta-analysis. Clinical Chemistry and Laboratory Medicine 2017; 55:167-180. https://doi.org/10.1515/cclm-2016-0303 61 Azzopardi K, Gatt A, Chockalingam N et al. Hidden dangers revealed by misdiagnosed diabetic neuropathy: A comparison of simple clinical tests for the screening of vibration perception threshold at primary care level. Primary Care Diabetes 2018; 12:111-115. https://doi.org/10.1016/j. pcd.2017.09.004

62 Armstrong DG, Lavery LA, Vela SA et al. Choosing a practical screening instrument to identify patients at risk for diabetic foot ulceration. Archives of Internal Medicine 1998; 158:289-292. https://doi.org/10.1001/ archinte.158.3.289

$63 \mathrm{Hu}$ A, Koh B, Teo M-R. A review of the current evidence on the sensitivity and specificity of the Ipswich touch test for the screening of loss of protective sensation in patients with diabetes mellitus. Diabetology International 2021; 12:145-150. https://doi.org/10.1007/ s13340-020-00451-9

64 Dutta A, Rastogi A, Jude EB. Screening developments for the foot in diabetes. The Diabetic Foot Journal 2020; 23(2):62-69

65 Arnold JF. Vascular assessment of the lower extremity with a chronic wound. The Surgical Clinics of North America 2020; 100: 807-822. https:// doi.org/10.1016/i.suc.2020.05.008

66 Formosa C, Gatt A, Chockalingam N. A critical evaluation of existing diabetic foot screening guidelines. The Review of Diabetic Studies 2016; 13:158-186. https://doi.org/10.1900/rds.2016.13.158

67 Álvaro-Afonso FJ, García-Morales E, Molines-Barroso RJ et al.

Interobserver reliability of the ankle-brachial index, toe-brachial index and distal pulse palpation in patients with diabetes. Diabetes \& Vascular Disease Research 2018; 15:344-347. https://doi. org/10.1177/1479164118767599 68 Ming A, Walter I, Alhajjar A, et al. Study protocol for a randomized controlled trial to test for preventive effects of diabetic foot ulceration by telemedicine that includes sensor-equipped insoles combined with photo documentation. Trials 2019; 20:521. https://doi.org/10.1186/ s13063-019-3623-x

69 Crawford F, Cezard G, Chappell FM. The development and validation of a multivariable prognostic model to predict foot ulceration in diabetes using a systematic review and individual patient data meta-analyses. Diabetic Medicine 2018; 35:1480-1493. https://doi.org/10.1111/ dme. 13797

70 Soukup T, Lamb BW, Arora S et al. Successful strategies in implementing a multidisciplinary team working in the care of patients with cancer: an overview and synthesis of the available literature. Journal of Multidisciplinary Healthcare 2018; 11:49-61. https://doi.org/10.2147/jmdh. S117945

71 Taberna M, Gil Moncayo F, Jané-Salas E et al. The multidisciplinary team (MDT) approach and quality of care. Front Oncol 2020; 10:85-85. https://doi.org/10.3389/fonc.2020.00085

72 Brousseau-Foley M, Blanchette V. Multidisciplinary management of diabetic foot ulcers in primary cares in Quebec: can we do better? Journal of Multidisciplinary Healthcare 2020; 13:381-385. https://doi.org/10.2147/ jmdh.S251236

73 Musuuza J, Sutherland BL, Kurter S et al. A systematic review of multidisciplinary teams to reduce major amputations for patients with diabetic foot ulcers. Journal of Vascular Surgery 2020; 71:1433-1446. e1433. https://doi.org/10.1016/j.jvs.2019.08.244

74 Buggy A, Moore Z. The impact of the multidisciplinary team in the management of individuals with diabetic foot ulcers: a systematic review. J Wound Care 2017; 26:324-339. https://doi.org/10.12968/ jowc.2017.26.6.324

75 Nathan DM. The diabetes control and complications trial/epidemiology of diabetes interventions and complications study at 30 years: overview. Diabetes Care 2014; 37:9-16. https://doi.org/10.2337/dc13-2112 76 Nativel M, Potier L, Alexandre L et al. Lower extremity arterial disease in patients with diabetes: a contemporary narrative review. Cardiovascular Diabetology 2018; 17:138. https://doi.org/10.1186/s12933-018-0781-1 77 Fiordaliso F, Clerici G, Maggioni S et al. Prospective study on microangiopathy in type 2 diabetic foot ulcer. Diabetologia 2016; 59 :
1542-1548. https://doi.org/10.1007/s00125-016-3961-0 78 Hinchliffe RJ, Forsythe RO, Apelqvist J, et al. Guidelines on diagnosis, prognosis, and management of peripheral artery disease in patients with foot ulcers and diabetes (IWGDF 2019 update). Diabetes Metab Res Rev 2020; 36(Suppl 1):e3276. https://doi.org/10.1002/dmrr.3276

79 Popplewell MA, Davies $\mathrm{H}$, Jarrett $\mathrm{H}$ et al. Bypass versus angio plasty in severe ischaemia of the leg - 2 (BASIL-2) trial: study protocol for a randomised controlled trial. Trials 2016; 17:11. https://doi.org/10.1186/ s13063-015-1114-2

80 Doupis J, Lyons TE, Wu S et al. Microvascular reactivity and inflammatory cytokines in painful and painless peripheral diabetic neuropathy. The Journal of Clinical Endocrinology and Metabolism 2009; 94:2157-2163. https://doi.org/10.1210/jc.2008-2385

81 Lipsky BA, Senneville É, Abbas ZG et al. Guidelines on the diagnosis and treatment of foot infection in persons with diabetes (IWGDF 2019 update). Diabetes Metab Res Rev 2020; 36(Suppl 1): e3280. https://doi. org/10.1002/dmrr.3280

82 Edmonds M. Diabetic foot infection: dispelling the myths. Diabetic Foot $2005 ; 8(1): 4$

83 Berendt AR, Peters EJ, Bakker K et al. Diabetic foot osteomyelitis: a progress report on diagnosis and a systematic review of treatment. Diabetes Metab Res Rev 2008; 24 Suppl 1: S145-161. 2008/04/30. https://doi.org/10.1002/dmrr.836.

84 Gariani K, Pham TT, Kressmann B et al. Three versus six weeks of antibiotic therapy for diabetic foot osteomyelitis: a prospective, randomized, non-inferiority pilot trial. Clinical Infectious Diseases 2020. https://doi.org/10.1093/cid/ciaa1758

85 Dumville JC, Lipsky BA, Hoey C et al. Topical antimicrobial agents for treating foot ulcers in people with diabetes. The Cochrane Database of Systematic Reviews 2017; 6:Cd011038. https://doi.

org/10.1002/14651858.CD011038.pub2

86 Boulton AJ, Bowker JH, Gadia M et al. Use of plaster casts in the management of diabetic neuropathic foot ulcers. Diabetes Care 1986; 9: 149-152. https://doi.org/10.2337/diacare.9.2.149

87 Pizarro-Duhart G. Treatment of diabetic foot ulcers with total contact casts: a critical review of the current literature. J Wound Care 2005; 14 : 465-467, 469,470. https://doi.org/10.12968/jowc.2005.14.10.26852 88 Bus SA, Armstrong DG, Gooday C, et al. Guidelines on offloading foot ulcers in persons with diabetes (IWGDF 2019 update). Diabetes Metab Res Rev 2020; 36(Suppl 1):e3274. https://doi.org/10.1002/dmrr.3274 89 Bus S, Arts M, De Haart M et al. Data-driven directions for effective footwear provision in diabetic patients with a history of foot ulceration. Annals of Physical and Rehabilitation Medicine 2014; 57:e381. https://doi. org/10.1016/j.rehab.2014.03.1385

90 Armstrong DG, Nguyen HC, Lavery LA et al. Off-loading the diabetic foot wound: a randomized clinical trial. Diabetes Care 2001; 24 : 1019-1022. https://doi.org/10.2337/diacare.24.6.1019

91 Katz IA, Harlan A, Miranda-Palma B et al. A randomized trial of two irremovable off-loading devices in the management of plantar neuropathic diabetic foot ulcers. Diabetes Care 2005; 28:555-559. https://doi. org/10.2337/diacare.28.3.555

92 Piaggesi A, Macchiarini S, Rizzo L et al. An off-the-shelf instant contact casting device for the management of diabetic foot ulcers: a randomized prospective trial versus traditional fiberglass cast. Diabetes Care 2007; 30: 586-590. https://doi.org/10.2337/dc06-1750

93 Caravaggi C, Sganzaroli A, Fabbi M et al. Nonwindowed nonremovable fiberglass off-loading cast versus removable pneumatic cast (AircastXP Diabetic Walker) in the treatment of neuropathic noninfected plantar ulcers: a randomized prospective trial. Diabetes Care 2007; 30: 2577-2578. https://doi.org/10.2337/dc07-0990

$94 \mathrm{Wu}$ SC, Jensen JL, Weber AK et al. Use of pressure offloading devices in diabetic foot ulcers: do we practice what we preach? Diabetes Care 2008; 31:2118-2119. https://doi.org/10.2337/dc08-0771

95 Sinacore DR. Total contact casting for diabetic neuropathic ulcers. Physical Therapy 1996; 76:296-301. https://doi.org/10.1093/ptj/76.3.296 96 Dumont I, Tsirtsikolou DM, Lepage M et al. The Ransart boot- an offloading device for every type of Diabetic Foot Ulcer? EWMA Journal 2010; $10: 46-50$

97 Galstyan G, Udovichenko O. Efficacy of removable casts in difficult to off-load diabetic foot ulcers: a comparative study. The Diabetic Foot 2006; 9(4):204-209

98 Pryakhina, K, Ermolaeva O, Bublik, E et al. Efficacy of a reusable total-contact cast. The Diabetic Foot 2010; 13(1):18-24 99 Van De Weg FB, Van Der Windt DA, Vahl AC. Wound healing: total contact cast vs. custom-made temporary footwear for patients with diabetic foot ulceration. Prosthetics and Orthotics International 2008; 32 : 3-11. https://doi.org/10.1080/03093640701318672

100 McKibbon KA. Evidence-based practice. Bulletin of the Medical Library Association 1998; 86(3):396 